\title{
TOTAL SUSPENDED SOLID DISTRIBUTION ANALYSIS USING SPOT-6 DATA IN SEGARA ANAKAN, CILACAP
}

\author{
A. J. Dhannahisvara ${ }^{a}$ Hartono $^{a}$, P. Wicaksono ${ }^{a}$ (iD) , F. S. Nugroho ${ }^{\text {id }}$ \\ ${ }^{a}$ Department of Geographic Information Science, Faculty of Geography, Universitas Gadjah Mada, Yogyakarta, Indonesia \\ ${ }^{b}$ Remote Sensing Ground Station Parepare, National Institute for Space and Aeronautics, Indonesia
}

\section{Article Info:}

Received: 31 May 2017

in revised form: 30 June 2018

Accepted: 10 October 2018

Available Online: 25 October 218

\section{Keywords:}

Band Ratio, SPOT-6, Total Suspended Solid, Chlorophyll-a, Transformation indices

\section{Corresponding Author:}

Pramaditya Wicaksono

Remote-sensing Laboratory, Faculty of Geography, Universitas Gadjah Mada, Yogyakarta, Indonesia Email: prama.wicaksono@ugm.ac.id

\begin{abstract}
The spatial distribution and concentration of Total Suspended Solids (TSS) are one of the coastal parameters, which is required to be examined to understand the quality of the water. The rapid development of remote-sensing technology has resulted in the emergence of various methods to estimate TSS concentration. SPOT-6 data has spatial, spectral, and temporal characteristics that can be used to estimate TSS concentration. The purposes of this research are (1) to determine the best method for estimating TSS concentration, (2) to map TSS distribution, and (3) to determine the correlation between TSS concentration and chlorophyll-a concentration using SPOT-6 data in Segara Anakan. The estimation of TSS concentration in this research was performed using an empirical model built from SPOT-6 and TSS field data. Bands used in this research are single band data (blue, green, red, and near-infrared) and transformed bands such as band ratio (12 combinations), Normalized Difference Suspended Solid Index (NDSSI) and Suspended Solid Concentration Index (SSC). The result shows that blue, green, red, and near-infrared bands and SSC index significantly correlated to TSS. Afterward, regression analysis was performed to determine the function that can be used to predict TSS concentration using SPOT-6 data. Regression function used are linear and non-linear (exponential, logarithmic, second order polynomial, and power). The best model was chosen based on the accuracy assessment using Standard Error of Estimate (SE). The selected model was used to calculate total TSS concentration and was correlated with chlorophyll-a field data. The result of accuracy test shows that the model from the blue band has an accuracy of $70.68 \%$, green band $70.68 \%$, red band $75.73 \%$, near infrared band $65.58 \%$, and SSC $73.67 \%$. The accuracy test shows that red band produced the best prediction model for mapping TSS concentration distribution. The total TSS concentration, which was calculated using red band empirical model, is estimated to be $6.13 \mathrm{t}$. According to the correlation test, TSS concentration in Segara Anakan has no significant correlation with chlorophyll-a concentration, with a coefficient correlation value of -0.265 .
\end{abstract} Anakan, Cilacap. Geoplanning: Journal of Geomatics and Planning, 5(2), 177-188. doi: 10.14710/geoplanning.5.2.177-188

\section{INTRODUCTION}

Remote-sensing technology has the advantage of studying an object without having to go directly to the field (as in a terrestrial survey), and thus, the work becomes more efficient, both time, cost, and energy. Characteristics of remote-sensing images that vary both spectral, spatial, and temporal characteristics can be applied to identify some of the main characteristics of coastal and ocean, both physical, chemical, geological and biological (Lo, 1986). One of the parameters related to water quality in this study is Total Suspended Solid (TSS), which can be extracted from satellite images using certain approaches (Lo, 1986; Lim et al. 2013; Fauzi \& Wicaksono 2016; Yanti et al. 2016). Also, object analysis using satellite images will have a spatial reference, so that the relationship between specific objects can also be spatially-correlated. 
Segara Anakan waters located in the Cilacap Regency is semi-enclosed water, in the form of estuary ecosystems and lagoons with a narrow gap connected to the sea. The narrow gap becomes the entry point of seawater originating from the Indian Ocean, rendering the water in Segara Anakan brackish. The water has unique characteristics because they are affected by processes from land and ocean, and causing this region to be highly potential but also very dynamic and vulnerable (Daniel, 2007). One of the problems in Segara Anakan is sedimentation. According to UNEP (2015), increased sedimentation could potentially cause damage to coral reefs, seagrass, and mangrove ecosystems. Furthermore, a decreased penetration of sunlight in water may inhibit macro-algae growth and macrophytes, increases water temperature and inhibits natural vegetation growth, reduce oxygen content, increases siltation of estuaries, and lead to the increase of toxic chemicals, heavy metals, and nutrients with the further impact of eutrophication.

The rivers that empty into Segara Anakan is Citanduy, Cibeureum, Cimeneng, and Cikonde. These four rivers are the main contributor of materials from upstream and middle part of the watershed. These materials are called sediments. Sediment consists of two types: bed load and suspended load. Bed load is materials that have been deposited in the bottom of the water, while the suspended load is a suspended material in the water column. Total Suspended Solid (TSS) is one of the coastal parameters, whose distribution and concentration needs to be studied to determine the water quality. TSS is suspended materials (diameter $>1 \mu \mathrm{m}$ ) retained on a Millipore filter with a pore diameter of $0.45 \mu \mathrm{m}$. TSS consists of mud, fine sand, and microorganism's body (Nurandani, 2013).

The diversity of the phytoplankton can influence the formation of climate, through the scattering of sunlight radiation. Some of the most important physical factors affecting the presence of phytoplankton are the temperature and brightness of the waters (Daniel, 2007). Clear water facilitates the phytoplankton to photosynthesize because the sunlight can penetrate the water column. Turbid water may be indicated by the amount of TSS and may inhibit the penetration of sunlight. Additionally, as described in UNEP (2015), the impact that can occur if TSS contains excess nutrients, such as phosphate waste $\left(\mathrm{PO}_{3}-\right)$ derived from fertilizers, can cause blooming of phytoplankton and algae.

The distribution and concentration of TSS need to be assessed to determine the quality of the water and can be used as a reference for more appropriate coastal area management. TSS is one component of water that can be extracted using remote-sensing technology (Lo, 1986). The remote-sensing satellite image, which has the spectral, spatial, and temporal characteristics that can be used for extracting TSS information, is SPOT-6 image with $6 \mathrm{~m}$ spatial resolution. SPOT- 6 has four multispectral bands, which are three visible bands and a near-infrared (NIR) band. These bands can be used to study the conditions of the water body using remote-sensing (TSS, phytoplankton, dissolved organic matter, and mineral particles) (Doxaran et al., 2002)

Each water has different TSS characteristics, thus, inducing various proposed methods for TSS mapping using remote-sensing data (Imen et al. 2015; Dorji \& Fearns 2016; Dorji \& Fearns 2017). Various combinations of bands and image transformations can be used to extract information regarding TSS (Lim et al.2013; Fauzi \& Wicaksono 2016). According to Robinson (2004) in Lee (2011), various types and concentration of suspended sediment were related to reflectance at the specific spectral wavelength. Water with TSS has a higher spectral reflectance characteristic with increasing wavelengths. The higher the concentration of TSS, the higher the reflectance value. Lodhi et al. (1997) in Jensen (2014) also concluded that the visible wavelengths $(0.580-0.690 \mu \mathrm{m})$ can be used to obtain information regarding suspended sediment types, while the near-infrared wavelengths $(0.714-0.880 \mu \mathrm{m})$ can be used to determine the amount of suspended sediment when the suspended sediment is the dominant element in the water column.

The aims of this research are (1) to map TSS concentration in Segara Anakan using SPOT-6 image, (2) to identify the best input, between reflectance bands (blue, green, red, near infrared), band ratio transformation, Normalized Difference Suspended Solid Index (NDSSI), and Suspended Solid Concentration Index (SSC) in mapping and estimating TSS distribution, and (3) to correlate TSS estimation results with chlorophyll-a content in Segara Anakan water. The research was conducted in Segara Anakan water of Cilacap Regency, Central Java Province. Segara Anakan is semi-enclosed water sheltered by Nusakambangan Island. The total area of Segara Anakan is about 24,000 hectares, including water, mangrove forests, and muddy lands formed by sedimentation (Yuliarko, 2010). 


\section{DATA AND METHODS}

\subsection{Data}

In this research we used SPOT-6 image part of Cilacap Regency (Segara Anakan), recorded on 25 January 2016 (Figure 1) and Landsat 8 OLI image of Central Java, recorded on 4 April 2016. Indonesia base map (scale 1 : 25.000), sheet Kalipucung 1308-241, Pengolahan 1308-242, Gandrungmangu 1308-243, Kawonganten 1308-244, and Geology Map, sheet Pangandaran, Jawa 1308-2 (1:100.000) were also used.

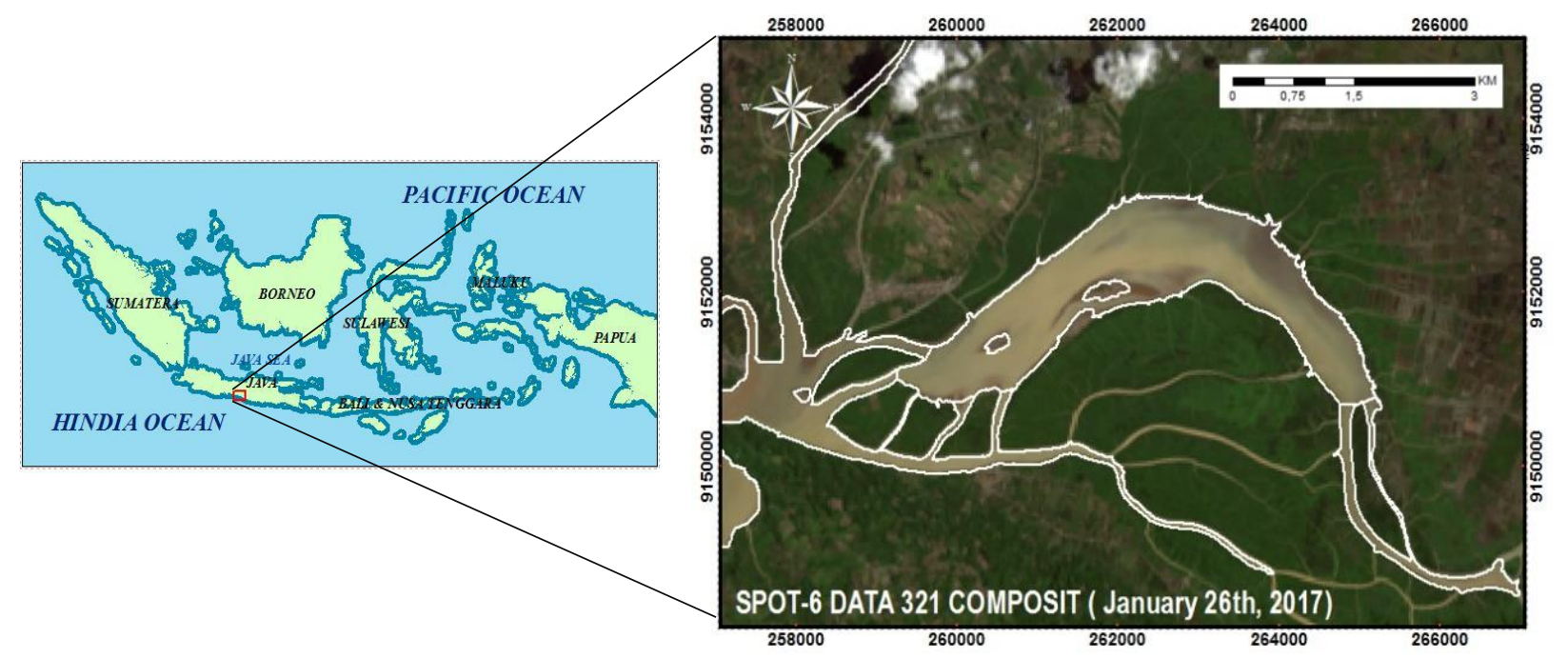

Figure 1. Research location at Segara Anakan, Cilacap Regency.

\subsection{Image pre-processing}

The pre-processing procedure of the remote-sensing data covers geometric correction, radiometric correction, atmospheric correction, image masking, image transformation, and determining the location of the sample. The SPOT-6 image product used is the primary product, that is, georeferencing has not been done yet and has no coordinate system. Therefore, geometric correction is needed. A geometric correction was done by registering the image, based on Ground Control Points (GCPs) obtained from Google Earth Image. The topographic condition of the study area is suitable for the $2^{\text {nd }}$ order polynomial transformation, which according to Danoedoro (2012), the amount of GCP required for geometric correction is at least 12 points. The radiometric corrections performed include sensor calibration, sunlight correction, and atmospheric correction. The atmospheric correction used the relative atmospheric correction method of Dark-Object Subtraction (DOS). The sampling technique used is Stratified Random Aligned Sampling with the help of transect line. The strata used is mapping units obtained from the result of density slice method on SSC transformation result.

\subsection{Field survey}

A field survey was conducted on 8 June 2016. Water samples were collected using water sampler at a depth of $0.3 \mathrm{~m}$. In accordance with Congalton \& Green (2009), the optimum depth of TSS sampling is shallower than $0.5 \mathrm{~m}$. Water samples were stored in a dark bottle to avoid the effects of sunlight since they will be tested for TSS and chlorophyll-a. The number of samples obtained was 58. Based on laboratory tests, 20 samples had poor results so that the samples used were only 38, where 20 samples (Figure 2) were used for empirical modeling, and 18 samples were for accuracy assessment of the model. 


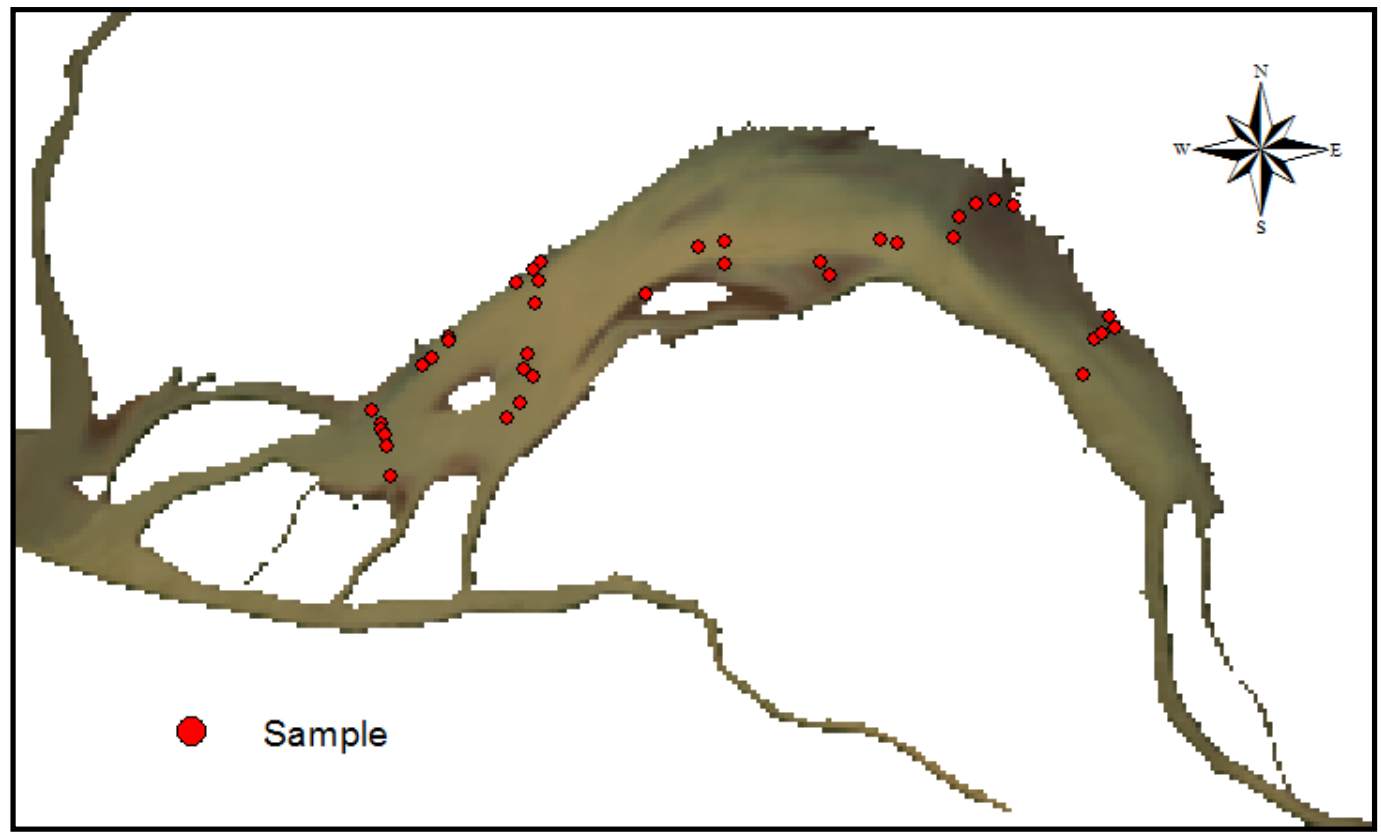

Figure 2. Sample locations across the study area.

\subsection{TSS mapping}

TSS mapping was performed by empirical modeling between SPOT-6 image with TSS field data. The input for modeling were reflectance bands (blue, green, red, and near-infrared (NIR)), band ratio transformation, SSC index transformation (Li, 2010) and NDSSI (Hossain et al., 2007). To obtain the TSS empirical model, statistical analysis is needed, i.e., data normality test, Pearson Product Moment correlation analysis, and regression analysis. The data normality test is performed because the analysis is categorized in parametric inferential statistics, and thus the data must be normally-distributed. Correlation analysis aims to determine the relationship between image pixel values with TSS field data. Inputs with significant correlation with TSS were used in the regression analysis to obtain regression functions that can be used to predict TSS concentrations from the SPOT-6 image in Segara Anakan. The regression analyses applied were linear and non-linear regression model. The non-linear models used were logarithmic, exponential, second order polynomial, and power. Regression analysis produces the coefficient of determination $\left(R^{2}\right)$ and resultant regression function. The $R^{2}$ describes the total variation of the dependent variable (TSS) that can be explained or predicted by the variation of independent variables (image pixel values).

The predicted TSS model was tested for accuracy using the Standard Error of Estimate (SE) method. Since the SE value does not show the accuracy percentage of the mode, the calculation of percentage accuracy was conducted by calculating upper range, lower range, minimum error, and maximum error based on 95\% confidence level from the mean (Wicaksono et al. 2011; Wicaksono et al. 2016). The TSS map was obtained from the model with the highest accuracy and the lowest SE value and then used to estimate total TSS across the study area. The total TSS was estimated by calculating the total TSS per pixel, then the total TSS of all pixels in the study area was summed. In accordance with the depth of sampling, the estimated total TSS is assumed to be up to the depth of $0.3 \mathrm{~m}$.

\subsection{Correlation analysis of TSS and chlorophyll-a}

The value of TSS in the location of field chlorophyll-a data was extracted and correlation analysis between modeled TSS and field chlorophyll-a data was performed. The value of modeled TSS was extracted from TSS concentration map with the highest accuracy. This analysis was used to determine the relationship between the concentration of TSS and chlorophyll-a, particularly in the Segara Anakan water. 


\section{RESULTS AND DISCUSSION}

\subsection{Empirical modeling}

Based on the Kolmogorov-Smirnov test results in Table 1, both TSS and chlorophyll-a field data were normally distributed. Correlation analysis was performed to determine the relationship between image pixel value and TSS. The input band is considered to have a significant correlation with TSS if the correlation coefficient value $(r)$ is above $0.444(95 \% \mathrm{CL}, \mathrm{n}=20)$. Based on Table 2 , inputs that are significantly correlated with TSS are all visible bands (blue, green, and red) and SSC. Input having the highest correlation with TSS is green band with $r$ of 0.590 , while the lowest is band ratio between green and red band (B1/B2, $r=-0.081$ ).

Table 1. The result of data normality test using Kolmogorov-Smirnov test.

\begin{tabular}{|ccc|}
\hline Statistics & TSS & Chlorophyll-a \\
\hline Sample No. & 20 & 20 \\
\hline Mean & 23.89 & 1.62 \\
\hline Standard deviation & 11.24 & 1.36 \\
\hline$D_{n}$ & 0.19 & 0.23 \\
\hline KS table (0.05) & 0.29 & 0.29 \\
\hline
\end{tabular}

Table 2. Correlation analysis between reflectance bands, NDSSI, and SSC with field TSS data.

\begin{tabular}{lccccc}
\multicolumn{1}{c}{ Input } & $\boldsymbol{R}$ & Band ratio & $\boldsymbol{r}$ & Band ratio & $\boldsymbol{r}$ \\
\hline B0 (blue) & $0.504^{*}$ & B0/B1 & 0.391 & B2/B0 & -0.379 \\
B1 (green) & $0.590^{*}$ & B0/B2 & 0.354 & B2/B1 & 0.150 \\
B2 (red) & $0.567^{*}$ & B0/B3 & 0.345 & B2/B3 & 0.279 \\
B3 (NIR) & $0.482^{*}$ & B1/B0 & -0.420 & B3/B0 & -0.326 \\
NDSSI & 0.333 & B1/B2 & -0.081 & B3/B1 & -0.087 \\
SSC & $0.535^{*}$ & B1/B3 & 0.219 & B3/B2 & -0.201 \\
$*$ significant at 95\%CL & & & & &
\end{tabular}

Table 3 shows the model that produced the highest and the most consistent $R^{2}$ is the power model, except on green band. Non-linear models produced higher mean values of $R^{2}$ than the linear model because the nature of the relationship between pixel values and field TSS is non-linear. TSS variation is very complex and dynamic. Hence, it is difficult for the TSS to correlate linearly with the reflectance value, primarily since the reflectance value of particular water body pixel is also contributed from the reflection of various objects within the water column. Consequently, the non-linear models delivered higher $R^{2}$ values due to the capability to follow the sample distribution more flexible. Scatter plot of the regression analysis result can be seen in Figure 3.

Accuracy assessment was performed to measure the quality of the resulting model. In addition, accuracy assessment was also conducted to determine the best model for TSS mapping in Segara Anakan water using the SPOT-6 image. Although the value of $R^{2}$ may represent the strength of the relationship between the two variables better than the value of $r$, the $R^{2}$ value cannot be used as a reference in determining the best regression model as it only represents the amount of TSS variation explained by the pixel values. Therefore, SE calculation was done to obtain the absolute accuracy of the model. According to Table 4, TSS empirical model from the red band using power regression model has the highest accuracy. This model produced SE of $6.68 \mathrm{mg} / \mathrm{l}$, with a maximum accuracy of $75.72 \%$. Model with the lowest accuracy was generated from NIR band using a logarithmic regression model with SE of $9.48 \mathrm{mg} / \mathrm{l}$ and maximum accuracy of $65.59 \%$. 
Table 3. Results of regression analysis between image pixel values and field TSS data.

\begin{tabular}{|c|c|c|}
\hline Model & Regression function & $R^{2}$ \\
\hline \multicolumn{3}{|c|}{ Blue band } \\
\hline Linear & 621.07BLUE + 10.703 & 0.254 \\
\hline Exponent & $12.014 \mathrm{e}^{27.512 B \text { BUE }}$ & 0.288 \\
\hline Logarithmic & $9.9538 \ln (B L U E)+63.521$ & 0.263 \\
\hline $2^{\text {nd }}$ order polynomial & $-20290 \mathrm{BLUE}^{2}+1386.8 \mathrm{BLUE}+5.1933$ & 0.266 \\
\hline Power & 130.25BLUE ${ }^{0.4519}$ & 0.313 \\
\hline \multicolumn{3}{|c|}{ Green band } \\
\hline Linear & 374.67GREEN + 0.2412 & 0.348 \\
\hline Exponent & $7.4603 \mathrm{e}^{16.804 \text { GREEN }}$ & 0.404 \\
\hline Logarithmic & $19.366 \ln ($ GREEN $)+78.299$ & 0.329 \\
\hline $2^{\text {nd }}$ order polynomial & 3444GREEN ${ }^{2}-19.127$ GREEN + 10.354 & 0.354 \\
\hline Power & 259.1 GREEN ${ }^{0.8852}$ & 0.398 \\
\hline \multicolumn{3}{|c|}{ Red band } \\
\hline Linear & $331.38 R E D+4.2094$ & 0.321 \\
\hline Exponent & $9.3574 \mathrm{e}^{14.044 \mathrm{RED}}$ & 0.333 \\
\hline Logarithmic & $17.136 \ln ($ RED $)+73.275$ & 0.312 \\
\hline $2^{\text {nd }}$ order polynomial & 1108.3RED ${ }^{2}+203.15 R E D+7.527$ & 0.323 \\
\hline Power & 188.46 RED $^{0.7525}$ & 0.348 \\
\hline \multicolumn{3}{|c|}{ NIR band } \\
\hline Linear & $290.02 \mathrm{NIR}+7.2367$ & 0.232 \\
\hline Exponent & $10.869 \mathrm{e}^{11.917 \mathrm{NIR}}$ & 0.226 \\
\hline Logarithmic & $18.108 \ln (\mathrm{NIR})+76.448$ & 0.238 \\
\hline $2^{\text {nd }}$ order polynomial & $340.08 N^{2} R^{2}+243.84 N I R+8.654$ & 0.232 \\
\hline Power & $208.25 \mathrm{NIR}^{0.7816}$ & 0.256 \\
\hline \multicolumn{3}{|c|}{ SSC } \\
\hline Linear & $139.22 \mathrm{SSC}+7.7078$ & 0.286 \\
\hline Exponent & $11.09 \mathrm{e}^{5.7143 \mathrm{sSC}}$ & 0.279 \\
\hline Logarithmic & $15.295 \ln (\mathrm{SSC})+57.879$ & 0.289 \\
\hline $2^{\text {nd }}$ order polynomial & $-41.85 S S C^{2}+149.73 S S C+7.126$ & 0.286 \\
\hline Power & $93.137 \mathrm{SSC}^{0.6587}$ & 0.310 \\
\hline
\end{tabular}
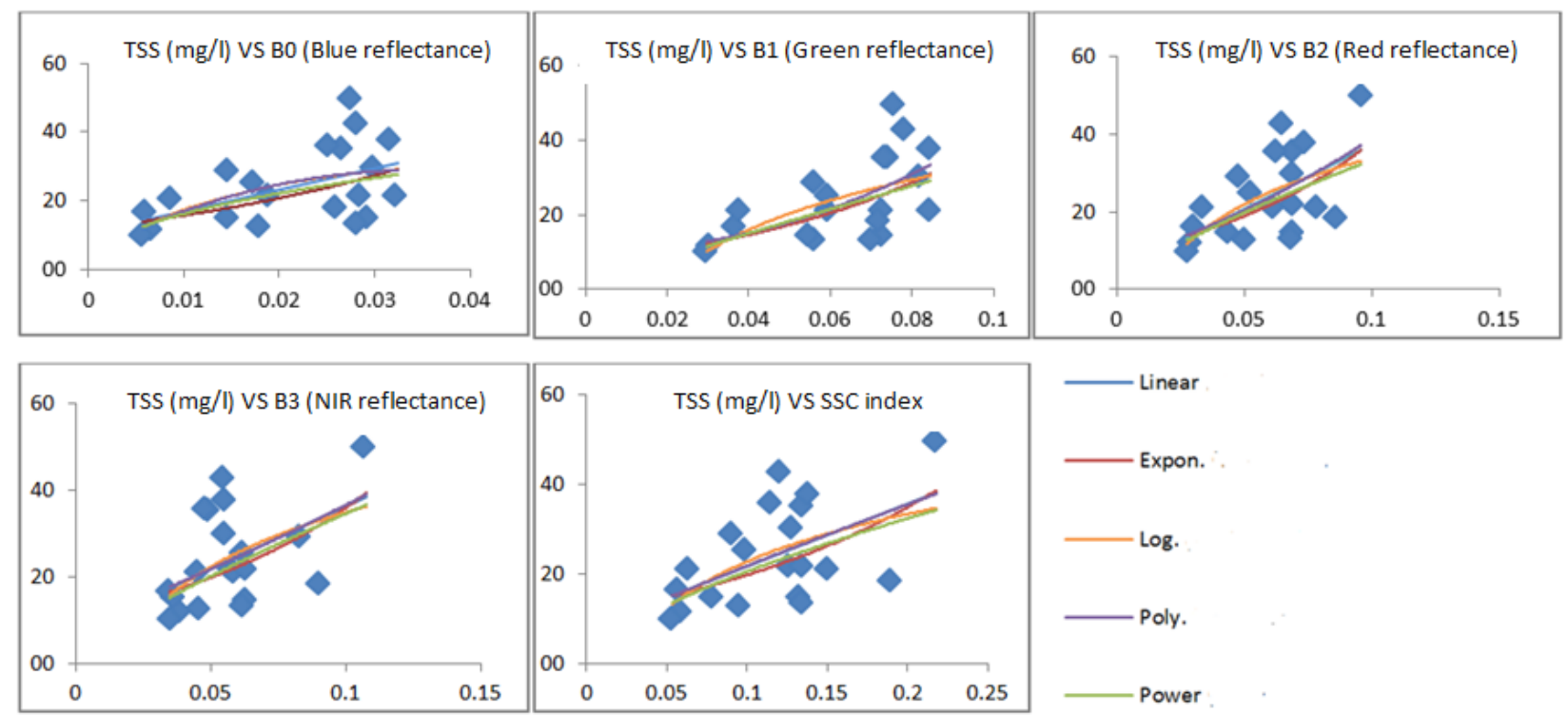

Figure 3. Regression models between image pixel values and field TSS data. 
Table 4. Accuracy assessment result of different TSS empirical models.

\begin{tabular}{|c|c|c|}
\hline Model & SE (mg/l) & Accuracy (\%) \\
\hline \multicolumn{3}{|c|}{ Blue } \\
\hline Linear & 8.77 & 68.17 \\
\hline Exponent & 8.07 & 70.68 \\
\hline Logarithmic & 8.51 & 69.09 \\
\hline $2^{\text {nd }}$ order polynomial & 8.70 & 68.41 \\
\hline Power & 8.12 & 70.51 \\
\hline \multicolumn{3}{|c|}{ Green } \\
\hline Linear & 8.70 & 68.39 \\
\hline Exponent & 8.10 & 70.59 \\
\hline Logarithmic & 8.58 & 68.83 \\
\hline $2^{\text {nd }}$ order polynomial & 8.98 & 67.39 \\
\hline Power & 8.07 & 70.68 \\
\hline \multicolumn{3}{|c|}{ Red } \\
\hline Linear & 6.73 & 75.58 \\
\hline Exponent & 6.76 & 75.44 \\
\hline Logarithmic & 6.80 & 75.30 \\
\hline $2^{\text {nd }}$ order polynomial & 6.72 & 75.61 \\
\hline Power & 6.69 & 75.72 \\
\hline \multicolumn{3}{|c|}{ NIR } \\
\hline Linear & 10.41 & 62.21 \\
\hline Exponent & 12.23 & 55.58 \\
\hline Logarithmic & 9.48 & 65.59 \\
\hline $2^{\text {nd }}$ order polynomial & 10.64 & 61.36 \\
\hline Power & 10.23 & 62.85 \\
\hline \multicolumn{3}{|c|}{ SSC index } \\
\hline Linear & 7.35 & 73.32 \\
\hline Exponent & 7.47 & 72.89 \\
\hline Logarithmic & 7.30 & 73.51 \\
\hline $2^{\text {nd }}$ order polynomial & 7.34 & 73.36 \\
\hline Power & 7.25 & 73.67 \\
\hline
\end{tabular}

Based on the results of accuracy assessment, the difference of accuracy between models is not much different, that is not more than $1.5 \%$, and the difference of SE is less than $1 \mathrm{mg} / \mathrm{l}$. Overall, power regression model produced the most accurate and consistent model, while for the lowest is the exponential model. This may be due to the trend of the correlation between image pixel values and field TSS data, which bend at the end of the line instead of full-straight, and the fittest curve is the power curve. The exponential model produced the lowest accuracy although the regression line is also bending. However, the curve formed by the exponential model is not representative of the TSS spectral response characteristics. Compared to the curve formed by other non-linear models, the curve of the exponential model curves down at the end of the line, while for other models they curved upward. This did not resemble TSS spectral response characteristics where water with higher TSS content will have higher spectral response across bands as well. In contrast, the exponential curve bent down at high TSS concentration.

All band ratios have a very low correlation with TSS concentration, and none is feasible for regression analysis. This may be due to the reflectance characteristics of TSS on each band, which is not significantly different. As a result, band ratio did not adequately represent the variation of TSS. As an example, band ratio between green and red band produced a very low correlation, which is -0.081 (B1/B2) and 0.150 (B2/B1). The reflectance characteristics of TSS on the green and red band are relatively similar; hence, when both bands is rationed, it produced a very low correlation with TSS. In order to maximize the performance of band ratio to explain the TSS concentration variations, the rationed bands must have different TSS spectral response characteristics. 
Based on the correlation analysis of SSC and NDSSI, only SSC index can be used to perform regression analysis with field TSS. The assumptions used by Hossain et al. (2014) in making the NDSSI algorithm is to add two bands with significantly different TSS spectral response, and divided by the difference of the reflectance on both bands. These bands are blue and NIR band. TSS reflectance is higher in NIR band and lower in blue band, and thus, the variation of TSS can be highlighted. However, in case of Segara Anakan, the TSS in water is not well-represented in NIR band, which resulted in a very low correlation of NDSSI and field TSS.

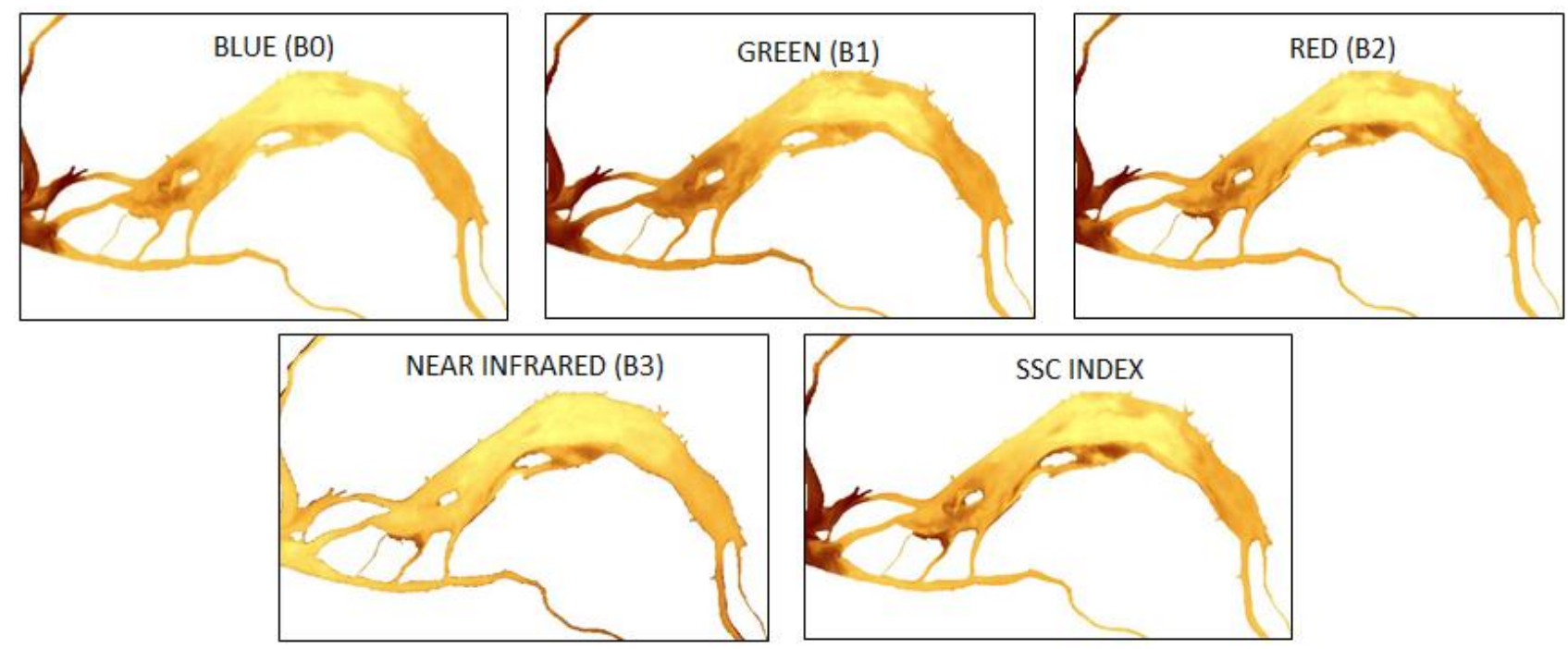

$0,4 \mathrm{mg} / \mathrm{l}$

$60 \mathrm{mg} / \mathrm{l}$

Figure 4. TSS distribution modeled from the best model of different inputs.

The SSC algorithm is more suitable to model TSS concentration in the study area than NDSSI. SSC algorithm uses green and red band. The SSC algorithm has the advantage of suppressing the interference of chlorophyll-a reflectance at low TSS concentration. In the SSC algorithm, pixel values of the green band are coupled with a red band and then divided by the ratio of the green and red band. The band ratio of the green and red band is what suppressed chlorophyll-a reflectance. Chlorophyll-a has high reflectance in green band and low reflectance in the red band because these energies are absorbed for photosynthesis. SSC transformation passed the correlation analysis because the bands used are the visible bands so that water absorption is not so high, and TSS variations can be represented in the image. Although SSC has a good correlation, the resulting TSS map does not produce the highest accuracy. This may be because SSC algorithm was developed using Landsat image (Li, 2010). The application of SSC algorithm on SPOT-6 image results slightly differently, as the sensitivity of SPOT-6 bands is different from Landsat bands. The study area characteristics of Li (2010) are also different, where Changjiang Estuary is dominated by water with high TSS concentration, i.e., up to $1,000 \mathrm{mg} / \mathrm{l}$. In contrast, Segara Anakan is a semi-enclosed lagoon and the water is not directly adjacent to the high seas but is connected by small gaps with medium TSS concentration, i.e., up to $61 \mathrm{mg} / \mathrm{I}$. This is what reduced the effectiveness of SSC algorithm in predicting TSS concentration in Segara Anakan.

Based on the TSS distribution maps in Figure 4, maps with higher accuracy show more varied TSS distribution. TSS map modeled from red band and SSC index, with $75.72 \%$ and $73.66 \%$ accuracy respectively, have better TSS concentration variation compared to blue and green bands with $70.68 \%$ and $70.68 \%$ accuracy respectively. Based on the accuracy, TSS map from red band and SSC index have higher accuracy than from blue and green band, whereas map produced by NIR band produced the lowest accuracy (62.84\%). Although there are some areas with high TSS concentration, the study area is dominated by water with low TSS concentration. This indicates that infrared channel reflection is very low 
because it is dominated by the absorption of radiation by water. TSS concentration is high only in the water close to the shoreline, and not too observable from the map. This further confirms that NIR band is less effective to explain the variation of TSS in water dominated by low TSS concentration.

Based on the analysis, it can be concluded that the use of NIR band for estimating TSS concentration in Segara Anakan water using the SPOT-6 image is not effective. This is not in accordance with research conducted by Jensen (2007) and Lo (1986), which states that NIR wavelength $(0.7-0.8 \mu \mathrm{m})$ is suitable to explain the variation of TSS. The assumption used was that water does not reflect NIR energies, hence very low reflectance, so when there is a high NIR reflectance from water body, it indicates the presence of TSS. However, this assumption is less appropriate when applied in Segara Anakan water, mainly due to the difference of TSS characteristics. In the study area, NIR band cannot represent the variation of TSS because, in some locations, the TSS concentration is low, hence strong water absorption is more dominant than TSS reflectance. The use of NIR band is more suitable for use in water with high and dominant TSS concentration, but not appropriate when used in water with low and dominant TSS concentration. This is contrast to the research conducted by Zheng (2015), where NIR band is suitable for TSS mapping. In contrast to the characteristics of TSS in Segara Anakan, Dongting Lake has higher TSS concentration with the highest TSS concentration of $88 \mathrm{mg} / \mathrm{l}$ (Zheng 2015). Meanwhile, in Segara Anakan the highest TSS concentration was only $42 \mathrm{mg} / \mathrm{l}$. Thus, the use of NIR band results in a better TSS distribution map when implemented in Dongting Lake because the TSS concentration is very high and dominant across the study area.

TSS prediction in areas with low TSS concentration can be performed using visible bands because on this spectrum the water still reflects the downwelling energies it receives so that the absorption feature is not dominated by water absorption. In this study, TSS map with the best accuracy was produced from the red band. Between the visible bands, the red band has the longest wavelength. In accordance with the reflectance characteristics of TSS within the water column, the reflectance will increase with increasing wavelengths. This also caused the blue band to be less effective to model TSS because, on blue band, water reflectance is more dominant than TSS. These results are almost similar to the previous study that red band (0.61-0.68 $\mu \mathrm{m})$ of the SPOT data was best suited to estimate TSS concentration, by reason of the low influence of chlorophyll and yellow substance and the range of gray value is adequate to describe the full range of concentrations (Lehner et al., 2004).

The use of various regression models did not show significantly different prediction. In general, the non-linear regression models have higher $R^{2}$ than linear regression model. This may be due to the highly complex and dynamic TSS characteristics, which are not likely to be linearly correlated to the image pixel values. Based on the previous studies related to TSS estimation using remote-sensing images, the best regression model used is non-linear regression model (Hung, 2014). The regression line generated by linear models cannot follow the trend of TSS sample variation, resulting in a low $R^{2}$ value.

The calculation of the total estimate of TSS up to the depth of $0.3 \mathrm{~m}$ equal to $6.13 \mathrm{t}$. This suspended material will eventually settle in the bottom of the water. This can lead to various problems such as silting and disruption of ecosystems in Segara Anakan. To date, no standardized method has been developed to map the TSS. This is because TSS variation is highly dynamic and complex, and the characteristics of TSS will vary with water and climates characteristics. Also, the variation of TSS's grain size, density, as well as the optical complexity of water body also influences the choice of mapping method to be used.

\subsection{Correlation analysis of TSS and Chlorophyll-a}

The result of correlation analysis between TSS and chlorophyll-a can be seen in Table 5 . The result of correlation analysis showed an $r$ value of -0.265 . This value indicates that TSS and chlorophyll-a have no significant correlation because the $r$ value is below 0.444 . A negative value indicates that when TSS gets lower, chlorophyll-a concentration gets higher and vice versa. This is in accordance with a theory that high TSS content can inhibit the growth of phytoplankton (UNEP, 2015). This may be due to the variables used was only TSS. TSS concentration does not fully determine the abundance of chlorophyll-a because the development of phytoplankton is not only influenced by water turbidity, but also other variables such as 
salinity, pH, temperature, Dissolved Oxygen content, and others (Daniel, 2010). The nature of the correlation between TSS and chlorophyll-a obtained in this study may not be universal.

Correlation analysis was also done based on the distribution of chlorophyll-a samples in a certain range. The chlorophyll-a data was grouped into 3 classes, i.e., $0-1 \mu \mathrm{g} / \mathrm{l}, 1.1-3.0 \mu \mathrm{g} / \mathrm{l}$, and $3.1-5.0 \mu \mathrm{g} / \mathrm{l}$. From Table 5 , it is clear that all ranges have positive relationship. The only significant correlation is at $0-1 \mu \mathrm{g} / \mathrm{l}$, with an $r$ value of 0.779 . This indicates that high chlorophyll-a concentration does not correlate with the abundance of TSS in the water. In contrast, the increase of chlorophyll-a concentration up to $1 \mu \mathrm{g} / \mathrm{l}$ is positively correlated with the TSS. Previous correlation analysis applied to all samples showed a negative correlation, but when the chlorophyll-a data was divided into different ranges, all ranges showed a positive correlation. Hence, the correlation analysis result between TSS and chlorophyll-a obtained in this study cannot be used as a reference, because the resulting nature of the relationship between the two variables is inconsistent. This may be due to the poor quality of chlorophyll-a data. However, this can also be caused by the small number of chlorophyll-a samples used in the analysis.

Table 5. Correlation analysis of TSS with chlorophyll-a at different concentration.

\begin{tabular}{|ccc|}
\hline Range $(\mu \mathrm{g} / \mathrm{l})$ & $\boldsymbol{r}$ & Sample No. \\
\hline $\mathbf{0 - 1 . 0}$ & $0.779 *$ & 10 \\
\hline $\mathbf{1 . 1 - 3 . 0}$ & 0.696 & 6 \\
\hline $\mathbf{3 . 1 - 5 . 0}$ & 0.248 & 4 \\
\hline
\end{tabular}

* significant at $95 \% \mathrm{CL}$

The inconsistent correlation analysis results between TSS and chlorophyll-a can also be caused by the error caused by the TSS empirical modeling process. As shown in Table 6, the correlation between reflectance bands and chlorophyll-a is consistent where visible bands have negative correlation value while NIR band has a positive correlation value. Negative correlation in visible bands is mainly caused by the strong chlorophyll-a absorption in visible bands. The green band also significantly correlated to the abundance of chlorophyll-a as this band is not strongly absorbed by chlorophyll-a compared to the blue and red band. In NIR band, the correlation is positive because chlorophyll-a in water column has similar reflectance characteristics to vegetation.

Table 6. Correlation analysis between reflectance bands and chlorophyll-a concentration.

\begin{tabular}{lcc|} 
& Band & $r$ \\
B0 (blue) & -0.259 \\
\hline B1 (green) & -0.451 \\
\hline B2 (red) & -0.247 \\
\hline B3 (NIR) & 0.471 \\
\hline
\end{tabular}

\section{CONCLUSION}

The best input in mapping TSS concentration distribution using SPOT-6 image in Segara Anakan water is the red band, using power regression model with SE of $6.69 \mathrm{mg} / \mathrm{l}$ and maximum accuracy of $75.72 \%$. The blue band produced TSS map with a maximum accuracy of $70.68 \%$, green band $70.68 \%$, NIR band $62.85 \%$, and SSC 73.66\%. Using the most accurate model, total TSS in Segara Anakan up to the depth of $0.3 \mathrm{~m}$, with a study area of 849.93 ha, is estimated to be around 6.13 tonnes of suspended solids. In our study area, TSS concentration has no significant correlation with the abundance of chlorophyll-a with $r$ of -0.265 (not significant at $95 \% \mathrm{CL}$ ). The value of $r$ between TSS and chlorophyll-a at $0-1 \mu \mathrm{g} / \mathrm{l}$ is 0.779 , at $1.1-3.0 \mu \mathrm{g} / \mathrm{l}$ is 0.696 and at $3.1-5.0 \mu \mathrm{g} / \mathrm{l}$ is 0.248 . The result of correlation analysis between TSS and chlorophyll-a obtained in this study may not be universal because the resulting nature of the relationship between the two variables is inconsistent. 


\section{REFERENCES}

Congalton, R. G., \& Green, K. (2009). Assessing the Accuracy of Remotely Sensed Data. Boca Raton: Taylor \& Francis Group.

Daniel. (2007). Struktur Komunitas Fitoplankton di Estuari Sungai Brantas, Jawa Timur. Skripsi. Bogor: Departemen Manajemen Sumberdaya Perairan Fakultas Perikanan dan Ilmu Kelautan Institut Pertanian Bogor.

Danoedoro, P. (2012). Pengantar Penginderaan Jauh Digital. Yogyakarta: Penerbit Andi.

Dorji, P., \& Fearns, P. (2016). A Quantitative Comparison of Total Suspended Sediment Algorithms: A Case Study of the Last Decade for MODIS and Landsat-Based Sensors. Remote Sensing, 8(10), 810. [Crossref]

Dorji, P., \& Fearns, P. (2017). Impact of the spatial resolution of satellite remote sensing sensors in the quantification of total suspended sediment concentration: A case study in turbid waters of Northern Western Australia. PLOS ONE, 12(4), e0175042. [Crossref]

Doxaran, D., Froidefon, J. M., \& Castaing, P. (2002). A Reflectance Band Ratio Used to Estimate suspended sediment concentration in sediment-dominated coastal water. int. j. remote sensing vol. 23, (pp. 5079-5085). France.

Fauzi, M., \& Wicaksono, P. (2016). Total Suspended Solid (TSS) Mapping of Wadaslintang Reservoir Using Landsat 8 OLI. IOP Conference Series: Earth and Environmental Science. 47(1), p. 012029. IOP.

Hossain, A. K., Jia, Y., \& Chao, X. (2007). Development of Remote Sensing Based Index for Estimating/Mapping Suspended Sediment Concentration in River or Lake Environments. Mississipi: ResearchGate.

Hossain, T. H., \& Tuyen, V. D. (2014). Estimating Suspended Sediment Concentrations in Surface Water of Tri An Lake (Vietnam) using Landsar Multispectral Images. Vestnik OrelGAU, (pp. 57-64). Hanoi.

Imen, S., Chang, N., \& Yang, J. (2015). Developing the Remote Sensing-based Early Warning System for Monitoring TSS Concentrations in Lake Mead. Journal of Environmental Management, 160, 73-89.

Jensen, J. R. (2013). Remote Sensing of The Environment An Earth Resource Perspective. England: Pearson.

Lee, M. S., Park, K. A., Chung, J. Y., Ahn, Y. H., \& Moon, J. E. (2011). Estimation of Coastal Suspended Sediment Concentration Using Satellite Data and Oceanic Insitu Measurement. Korean Journal of Remote Sensing, Vol.27, No.6, (pp. 677-692). Seoul.

Lehner, S., Anders, I., \& Gayer, G. (2004). High Resolution Maps of Suspended Particulate Matter Concentration in The German Bight. EARSeL eProceedings 3, (pp. 118-126). Germany.

Li, J., Gao, S., \& Wang, Y. (2010). Delineating Suspended Sediment Concentration Patterns in Surface Waters of Changjiang Estuary by Remote Sensing Analysis. Acta Oceanologica Sinica, 38-47.

Lim, H. S., MatJafri, M. Z., Abdullah, K., \& Asadpour, R. (2013). A two-band algorithm for total suspended solid concentration mapping using THEOS data. Journal of Coastal Research, 29(3), 624-630. [Crossref]

Lo, C. P. (1986). Penginderaan Jauh Terapan. Diterjemahkan oleh : Bambang Purbowaseso. Jakarta: Penerbit Universitas Indonesia (UI Press).

Nurandani, P. (2013). Pemetaan Total Suspended Solid (TSS) menggunakan Cltra Satelit Muultitemporal Di Danau Rawa Pening Provinsi Jawa Tengah. Jurnal Geodesi UNDIP Voume 2 Nomor 4.

UNEP. (2015). Sedimentation and Erosion. Retrieved Desember 26, 2015, from United Nation Environments Programme: http://www.cep.unep.org/publications-and-resources/marine-and-coastal-issueslinks/sedimentation-and-erosion

Wicaksono, P., Danoedoro, P., Hartono, H., Nehren, U., \& Ribbe, L. (2011). Preliminary work of mangrove ecosystem carbon stock mapping in small island using remote sensing: above and below ground carbon stock mapping on medium resolution satellite image. In Remote Sensing for Agriculture, Ecosystems, and Hydrology XIII (Vol. 8174, p. 81741B). International Society for Optics and Photonics.

Wicaksono, P., Danoedoro, P., Hartono, \& Nehren, U. (2016). Mangrove biomass carbon stock mapping of the Karimunjawa Islands using multispectral remote sensing. International Journal of Remote Sensing, 37(1), 26-52. 
Yanti, A., Susilo, B., \& Wicaksono, P. (2016). The Aplication of Landsat 8 OLI for Total Suspended Solid (TSS) Mapping in Gajahmungkur Reservoir Wonogiri Regency. IOP Conference Series: Earth and Environmental Science. 47(1), p. 012028. IOP.

Yuliarko, S. (2010). Permasalahan Kawasan Segara Anakan. 2-10.

Zheng, Z., Li, Y., Guo, Y., Xu, Y., Liu, G., \& Du, C. (2015). Landsat-Based Long-Term Monitoring of Total Suspended Matter Concentration Pattern Change in the Wet Season for Dongting Lake, China. Remote Sensing, 13976-13999. 